\title{
A Rare Case of Isolated Cysticercosis of Extensorcarpi Radialis Brevis Muscle near Elbow
}

\author{
MK Rajak *, Sachin kumar, Rajesh Thakur, Indronil Bhaduri and AK Choudhary \\ Department of orthopaedics, Tata Main Hospital, India
}

Received: March 27, 2018; Published: April 12, 2018

*Corresponding author: MK Rajak, Department of orthopaedics, Tata Main Hospital, Jamshedpur, India, Email: drmanojrajak@gmail.com

\begin{abstract}
Cysticercosis is a disease caused by cysticercuscellulosae, the larval form of tapeworm, Taeniasolium. Human cysticercosis occurs when eggs are ingested via faecal-oral transmission from an infected host. Humans become an accidental intermediate host, with development of cysticercosis within various organs. Isolated muscular involvement is rare with only a handful of cases reported in the literature. Involvement of the extensor carpi radialis brevis muscle is rarer with no such case reported. We present a case of isolated cysticercosis of the extensor carpi radialis brevis muscle that presented a diagnostic challenge. Initially treated on line of tennis elbow elsewhere, but diagnosed to be cysticercus cyst on high resolution ultrasound. The patient's infection was successfully managed non-operatively with oral antihelminthic and symptomatic treatment.
\end{abstract}

Keywords: Cysticercosis; Taeniasolium; Extensor Carpi Radialis Brevis Muscle; Ultrasound

\section{Introduction}

Cysticercosis is a systemic manifestation caused by dissemination of the larval form of the pork tapeworm, Taeniasolium. Human cysticercosis occurs when eggs are ingested via faecal-oral transmission from a tapeworm host. The human then becomes an accidental intermediate host, with development of cysticercosis within organs. In order of frequency, the occurrence of cysts in humans is the central nervous system, the eye, striated muscle, subcutaneous tissue, and rarely, other tissues [1]. Isolated muscular involvement is rare, and as the symptoms are non-specific, it presents a diagnostic dilemma for the treating surgeon. The clinical manifestations may vary depending on the site of involvement. High resolution USG is an inexpensive, readily available, and radiation-free modality for the diagnosis of soft tissue lesions. To our knowledge, this is the only case reported in extensor carpi radialis brevis muscle.

\section{Case report}

A 40-year old healthy female, housewife, right hand dominant, visited orthopaedic OPD in January 2015 with chief complaint of pain over lateral aspect of right elbow since 6 weeks. While doing household work, she developed pain over lateral aspect of right elbow which was constant and she also had difficulty in lifting weight. The pain was made worse by twisting movement of forearm and relieved by rest. The patient had not suffered any constitutional symptoms during this period. The patient's physical status was good and her medical and family history was insignificant. The patient was a non-vegetarian, but there was no history of pork or beef consumption. She had visited local physician and orthopaedic surgeon and was being treated on the line of tennis elbow. In spite of six weeks of treatment she continued to have pain and difficulty in using her dominant limb, so she visited our institution. On physical examination there was no obvious swelling, local warmth or erythema over the site of pain. Tenderness was elicited over lateral aspect of upper forearm just below elbow joint. Deep palpation could not be done because of pain. Range of motion of the elbow and shoulder joints were within normal limits and there was no evidence of distal neurovascular deficit.

The laboratory investigation which patient had was normal with no evidence of anemia or leucocytosis. Radiograph of the right elbow which patient had with her showed no calcification but there was inflammatory stranding in the subcutaneous fat (Figure 1). Taking soft tissue swelling in mind, patient was advised for high resolution ultrasound. High resolution ultrasound examination reported $2.5 \times 1.5 \times 1.3 \mathrm{~cm}$ size cystic lesion within the extensor carpi radialis brevis muscle below the right elbow joint with eccentric calcification within causing shadowing. The cystic lesion was tense and non-compressible. No abnormal vascularity was seen in the lesion or the periphery. The report was consistent with cysticercus cyst in the muscle (Figure 2). The patient was managed conservatively with oral antihelminthic medication (oral albendazole $15 \mathrm{mg} / \mathrm{kg} /$ day divided into two doses daily for 3 weeks) and symptomatic treatment (trypsin and chymotrypsin, piroxicam and omeprazole). The patient was followed up twice a week for the 
first week and then weekly thereafter for 4 weeks. Patient showed initial symptomatic relief from the second day of treatment and at the end of four weeks there was complete resolution of the swelling on palpation and the patient was essentially symptom free. On follow up at 8 months the patient had been managing well with activities of daily living and reported no further symptoms.
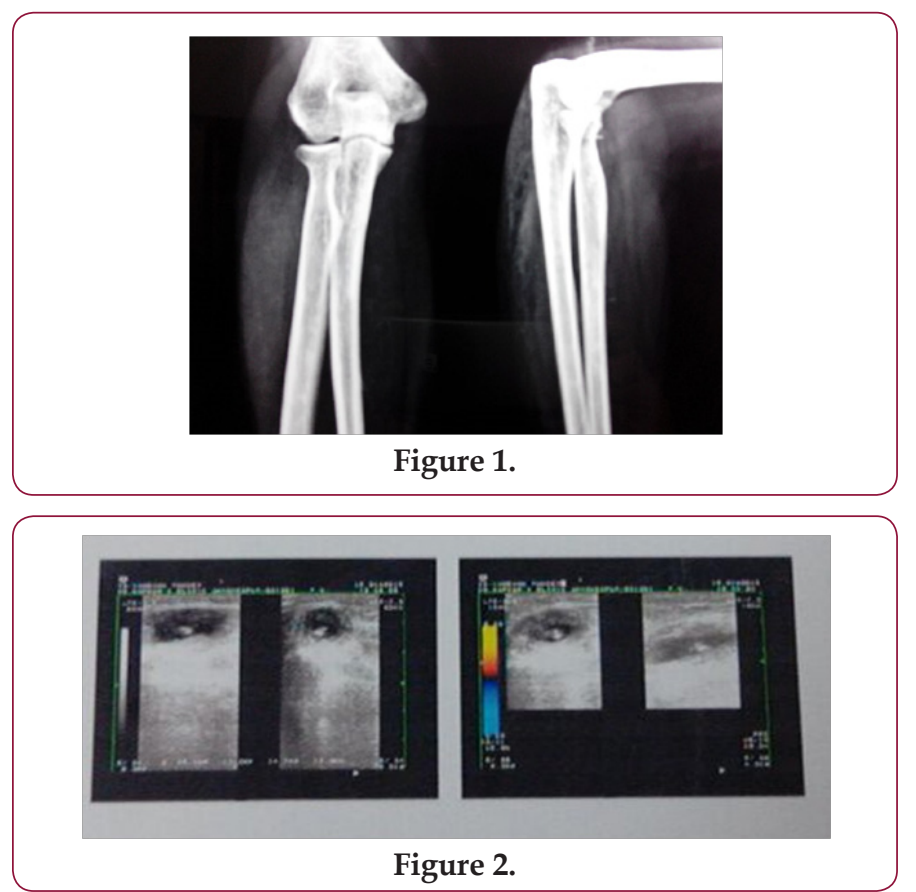

\section{Discussion}

Cysticercosis is a parasitic infection caused by Cysticercuscellulosae, the larval form of Taeniasolium. Humans are the only definitive host while both humans and pigs can act as intermediate hosts. Cysticercosis in humans is caused by consumption of food or water contaminated with viable eggs of T. solium or regurgitation of eggs into the stomach from the intestine of people harboring a gravid worm [1,2] If the eggs contaminate food sources, upon ingestion they develop into larvae and result in cysticercosis. Hence, even people who do not consume pork, including vegetarians, can develop cysticercosis [2,3]. Isolated muscular involvement is rare [4] and because of the non-specific symptoms it presents a diagnostic dilemma for the treating physician. Till date there are only a handful of cases of isolated intra-muscular cysticercosis reported in the literature [3-14]. In our case, we too faced a diagnostic challenge due to the rarity of this presentation. Most muscular cysticercosis is asymptomatic and goes unnoticed for the life of the patient. The clinical features depend on the location of the cyst, the cyst burden, and the host reaction. Subcutaneous cysticercosis may cause painless or painful subcutaneous nodules [2] Muscular cysticercosis may present clinically with myalgia, pseudotumoror mass and pseudohypertrophy [2-4] Clinically, soft tissue cysticercosis can be misdiagnosed as lipoma, epidermoid cyst, abscess, pyomyositis, tuberculous lymphadenitis, neuroma, neurofibroma, sarcoma, myxoma, ganglion, or fat necrosis [15-18].

High-frequency USG has become relatively inexpensive and is a readily available and reliable diagnostic modality for the diagnosis of soft tissue cysticercosis $[16,17,19]$. Although MRI is more specific for neurocysticercosis [17], CT may be the modality of choice for muscle cysts as it can demonstrate multiple cysts in a honeycomb or leopard skin pattern against a background of muscle mass [18]. Treatment of soft tissue cysticercosis depends on the location of the cysts [1] Surgical excision is done for isolated skeletal muscle or soft tissue cysticercosis associated with abscess. Recently, case reports have advocated non-operative management, even for painful masses, with antihelminthic medication and oral steroid therapy $[6,15,16]$. Follow-up USG is done after three weeks of antihelminthic medication to look for resolution of the lesion. Steroids are commonly used as a cover for the inflammatory response to the necrotic pathway. In our case, we instituted only oral antihelminthic (albendazole) and symptomatic treatment, with success. Steroid was not used.

\section{Conclusion}

Isolated muscular cysticercosisposes a diagnostic dilemma for treating physicians, thus, should always be part of the differential diagnosis of subcutaneous and intra-muscular swelling. High resolution USG is a good modality for diagnosing soft tissue cysticercosis.

\section{References}

1. Garcia HH, Gonzalez AE, Evans CA, Gilman RH (2003) Taeniasolium cysticercosis. Lancet 362(9383): 547-556.

2. Kraft R (2007) Cysticercosis: An emerging parasitic disease. Am Fam Physician 75(6): 91-98.

3. Kumar R, Singh V, Rastogi A, Ogilvie CM, Kasten $\mathrm{P}$, et al. (2001) Cysticercosis of the triceps--an unusual pseudotumor: case report and review. ClinOrthopRelat Res pp. 217-221.

4. Abdelwahab IF, Klein MJ, Hermann G, Abdul-Quader M (2003) Solitary cysticercosis of the biceps brachii in a vegetarian: a rare and unusual pseudotumor. Skeletal Radiol 32(7): 424-428.

5. Kumar BD, Dave B, Meghana SM (2011) Cysticercosis of masseter. Indian J Dent Res 22(4): 617.

6. Raj Kumar, Vinita Singh, Archana Rastogi (2005) Cysticercosis of temporalis muscle: a case report. J Pediatr Neurol 3(4): 269-272.

7. Nagaraj C, Singh S, Joshi A, Trikha V (2008) Cysticercosis of biceps brachii: a rare cause of posterior interosseous nerve syndrome. Joint Bone Spine 75(2): 219-221.

8. Sen K, Karmakar P, Bandyopadhyay A, Santra T, Sarkar M (2013) Cysticercosis involving muscles and liver only: A yet unknown entity. Ann Trop Med Public Heal 6(3): 350-352.

9. Sethi PK, Sethi NK, Torgovnick J, Arsura E (2007) Cysticercosis of temporalis muscle: an unusual cause of temporal headaches. A case report. J Headache Pain 8(5): 315-316.

10. Sharma R, Gautam P, Kumar S, Elhence P, Bansal R, et al. (2011) Isolated cysticercosiscellulosae of sternocleidomastoid muscle: a case report with review of literature. Indian J Otolaryngol Head Neck Surg 63(1): 127-130.

11. Singal R, Mittal A, Gupta S, Gupta R, Sahu P, et al. (2010) Intramuscular cysticercosis diagnosed on ultrasonography in thigh: A rare case report. N Am J Med Sci 2(3): 162-164.

12. Yue XH (1994) Fine needle aspiration biopsy diagnosis of cysticercosis. A case report. Acta Cytol 38(1): 90-92.

13. Singh S, Sreenivasan V, Garg K, Wazir ND, Rajput JS, et al. (2013) Cysticercosis involving muscle of mastication: a review and report of two cases. Case Rep Dent. 
14. Sharma SR, Sharma N, Yeolekar ME (2010) Carpal tunnel syndrome caused by cysticercosis. Indian J Plast Surg 43(2): 210-212.

15. Horton J (1996) Biology of tapeworm disease. Lancet 348(9025): 481.

16. Mittal A, Das D, Iyer N, Nagaraj J, Gupta M (2008) Masseter cysticercosis - a rare case diagnosed on ultrasound. Dentomaxillofac Radiol 37(2): 113-116.

17. Del Brutto OH, Wadia NH, Dumas M, Cruz M, Tsang VC, et al. (1996) Proposal of diagnostic criteria for human cysticercosis and neurocysticercosis. J Neurol Sci 142(1-2): 1-6.

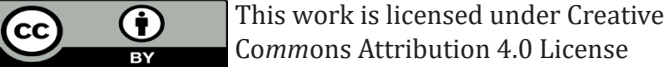

Submission Link: https://biomedres.us/submit-manuscript.php
18. Bhalla A, Sood A, Sachdev A, Varma V (2008) Disseminated cysticercosis: a case report and review of the literature. J Med Case Rep 2: 137.

19. Jhankaria BG, Chavhan GB, Krishnan P, Jhankaria B (2005) MRI and ultrasound in solitary muscular and soft tissue cysticercosis. Skeletal Radiol 34(11): 722-726.

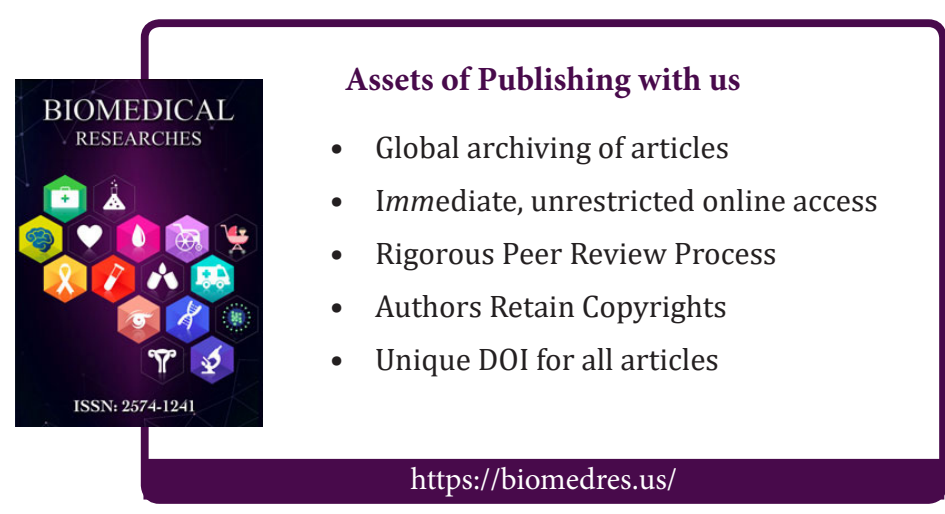

